\title{
Development of Massive Open Online Courses Based on 3D Computer Graphics and Multimedia
}

\author{
https://doi.org/10.3991/ijep.v9i4.10193 \\ Leonid L. Khoroshko ( $\left.{ }^{\varpi}\right)$, Peter A. Ukhov, Pavel P. Keyno \\ Moscow Aviation Institute (National Research University), Moscow, Russia \\ Khoroshko@mati.ru
}

\begin{abstract}
This work is devoted to the creation of a laboratory workshop (virtual) for open online courses based on programs of three-dimensional computer graphics and multimedia. The issues of using SolidWorks, Autodesk $\mathbb{}$ 3DS MAX software in distance learning are discussed. The software was used to prepare training materials for the courses "Theory of machines and mechanisms", "Computer Graphics" and "Engineering and Computer Graphics". Using the software product SolidWorks, Autodesk® 3DS MAX has significantly improved visual part of the course. Finally, authors has developed new software tools for organizing the independent work of students in an interactive mode. The article concludes with graphs of student performance in comparison with the previous grade.
\end{abstract}

Keywords - Online course, laboratory practical work, distance educational technologies, multimedia, computer graphics, content, interactive training.

\section{$1 \quad$ Introduction}

Mass usage of open online training courses for education in the sphere of engineering is a rather interesting subject matter. On the one side, it is impossible to achieve good results in the engineering training without the practical studies and creating actual physical objects. On the other side, the technological development has reached the level when the accessibility of some technologies, such as $3 \mathrm{D}$ printing from plastic materials, is a rather common thing. So, the development of a mass open online training course with practical studies is something that generates interest.

Distance learning technologies for education in engineering still involve significant limitations. Despite the development of software environments that allow designing items on PC, one of the most important issues is studying the peculiarities of the production process and the related risks. Engineering students must know the whole life cycle of a product. At the same time, it is also necessary to understand the risks arising in the process of design, supply, procurement, logistics, manufacture and operation. Based on this the parameters of the production life cycle may sometimes be changed for financial reasons [1].

The selected online learning model for the technical subjects is blended learning. It allows working with students in the design process using only distance learning, and 
study the manufacturing process and related risks using laboratory equipment and the university facilities. Also, items that are not approved by the teacher are not included in the final purchase order list.

For the development of the learning objects within the theoretical studies, graphic editor and 3D modeling were widely used. 3D models in the materials of the training courses considerably facilitate the understanding and help the students to get accustomed to working with an electronic prototype of the product.

As an example, the work includes a course "Theory of machines and mechanisms", which includes a set of laboratory researches and a final task - a course project. The project is completed by the students within one semester (five months). Total duration of the course work includes purchasing and assembly of the designed mechanism. The production technology is FDM 3D printing from plastic [2].

The article describes in detail the new methodology, which has significantly increased the involvement of students in the technological processes of developing assembly mechanisms. The presented technique allowed the student to acquaint the student with all stages of the product life cycle in visual form. Thanks to the implementation of this method, the performance of each student has significantly increased. This is supported by relevant statistics.

The proposed method is universal, and each process can be changed to the needs of the corresponding product. It is also noted that all technological processes can be divided between different teachers. Thus, the basics of conveyor production are being introduced. The most important feature is the fact that all the sketches of mechanisms can be prepared for printing on a 3D printer, and the student himself can in practice verify the correctness of his engineering research.

\section{Multimedia and Special Software the Use of 3D Modeling}

The use of 3D modeling application suites allows to create complex models of geometry objects, as well as carrying out real time dynamic modeling technological process of construction, consisting of many parts. As a versatile components Unigraphics, Solid Works, Autodesk Inventor, 3DS MAX and other software systems were used. Application of that software/hardware suites allows to automate complex system design process, while imitation modeling allows to track all the object parameters changes: their forms, dimensions, position, material characteristics etc. (Fig. 1).

Autodesk Inventor, 3DS MAX and Solid Works 3D design software systems were used to research kinematic of assembly process. Use of this application suites allowed to create a wide class of parts with curvilinear generatrix, but moreover to model a real time deformation process. Different object categories, such as "Geometry", "Shapes", "Space Wraps" etc. were used to model 3D objects of complex geometry form with curvilinear generatrix, joint constructions and equipment for deformation process. Complex geometry models, consisting of multiple parts are created using this and other categories of Autodesk Inventor and Solid Works objects, as well as wide variety of precision modeling facilities. Possibilities gained by use of this software suites allowed to model 3D objects with granting the real deformation, imitating dif- 
ferent power impact. Modeling was handled with use of keyframe-based animation principles.

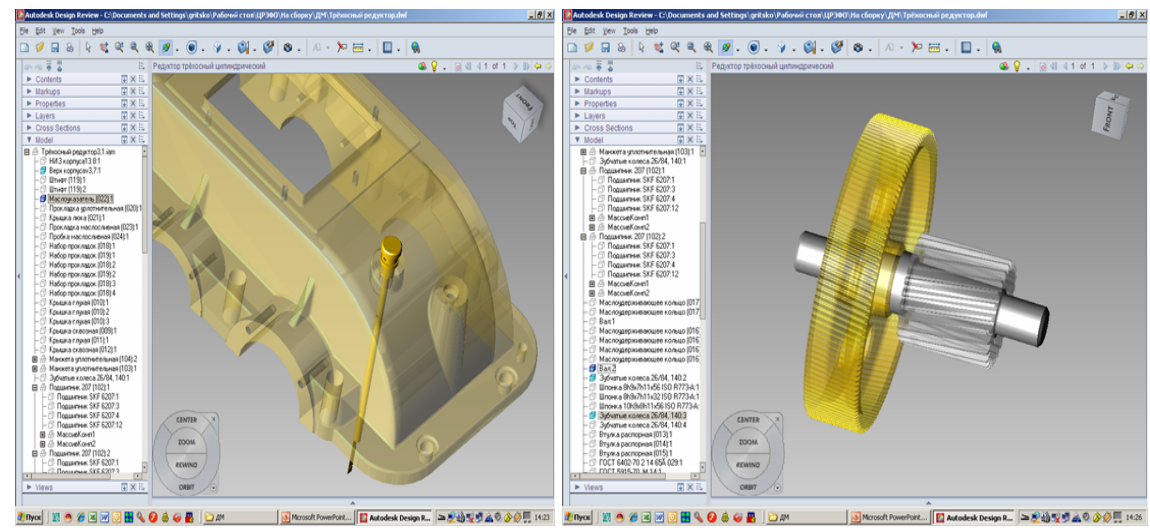

Fig. 1. The use of $3 \mathrm{D}$ modeling

Modeling was handled with use of keyframe-based animation principles for main stages of assembly process. Modeling with use of animation principles is an automated process of image sequence, each of which shows some change in the assembly state. This changes affected mutual objects and sub objects position, their form, described by different modifications, deformations, object material properties, etc., i.e. modeling was handled considering physical characteristics of object surface materials, such as elasticity, static friction factor and sliding friction, as well as physical influence on objects, as pressure, imitated by volume deformation emitters, object collisions, which results depended on the speed of objects and physical properties of their materials. Animation process automation consisted in assignment of parameters to be animated in keyframes, which divided into interstitial and, according to them, time shifting diagram was created as an animation track. In that way, the use of computeraided principles (CAD/CAM/CAE) and technologies allows to create multilevel 3D models and build mathematical models of dynamic processes on all production's phases and complex construction exploitation.

SolidWorks design environment was used extensively for the development of the theoretical part of the training course. The mentioned environment has a short learning curve and is understood rather quickly by the students without any particular problems.

The theoretical part of the training course had a set of 3D models of various mechanisms developed on the basis of the given requirements. A gearbox mechanism is taken as an example (Fig. 2).

Besides this, the theoretical part of the course has animation elements for the operation demonstration of the machines and mechanisms and numerous links to development projects for special mechanisms: Walt Disney, Tenfold engineering and other companies' projects. There are a lot of different mechanisms that can be selected as a prototype for design [3]. 


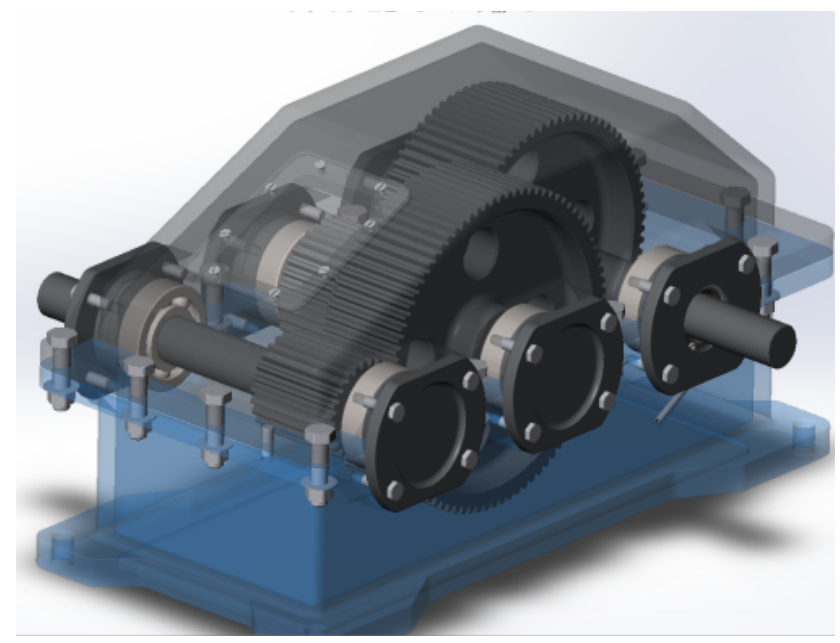

Fig. 2. Generic industrial gearbox

\section{$3 \quad$ Modeling in Solid Works and 3DS MAX Visualization}

The first stage of work for the students is modelling the future product together. Students are divided into work groups of 3 people each and model a selected mechanism or a device. In the system there is a selection of previously created mechanisms as examples for the students, but particular design features and information about components are not included in this selection. Mechanisms with control systems may also be selected as the students take the course of electrical equipment and electronics parallel to the project.

As a modelling environment we have chosen SolidWorks as it can be used to not just design and manage the assembly of the products, but to calculate the products' strength at the sufficient level for the implementation. A number of the mechanisms in the examples are made so that the limits of the products' strength do not apply. This circumstances require optimization and modification of the structural image of the mechanisms.

The kinematic characteristics are studied during the assembly, and the connections and the relations for parameters calculations are selected reasonably. Further on these parameters are monitored in the finished product.

The products are modelled on the personal computers of the students (student version) or using a remote connection to applications server (commercial version). At the same time the teacher checks the work at each stage of design [4].

The following design steps are performed consecutively:

- Calculations for the structural arrangement of the mechanisms using alternative structural arrangements

- Determining the kinematic parameters of the mechanism

- Draft design of each structural part in SolidWorks 
- Assembly of the mechanism in SolidWorks considering the tolerances, fit and manufacturing gaps

- Analysis of the kinematic parameters in SolidWorks

- Analysis of the strength parameters and strength calculation for the critical parts in SolidWorks

- Visualization of each part in Autodesk ${ }^{\circledR}$ 3DS MAX

- Final adjustments of the models before 3D printing considering to the chosen technology

At each step the design is improved and reworked considering the newly discovered input data. There is also a simulation of the parameter's modification during the design process and of various situations when the priorities change during the design of one or another mechanism. Fig. 3 shows the strength calculation of the frame of a quadcopter for the most heavy-duty conditions, as an example.

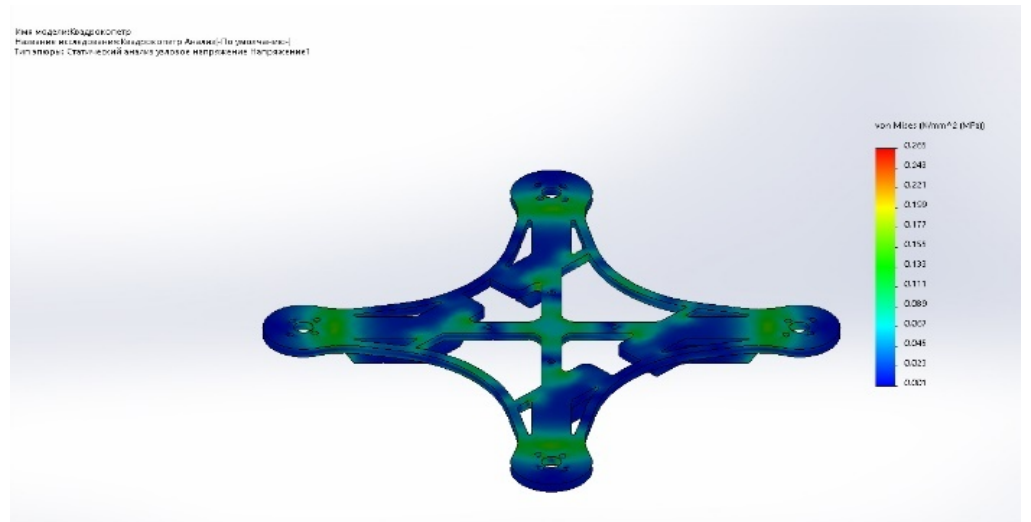

Fig. 3. Strength calculation of the frame of a quadcopter

All the models and parts are stored in the Intermech Search TDM system and are available for the teacher. The students receive messages through the system and through the life cycle management system as well. Presently many variants of using different PLM systems are being developed, IM Project was used in the first stream.

\section{Effectiveness Evaluation of the Implemented Learning Method}

We have combined the steps from the previous paragraph into more general technological processes. The tools used in each process are interchangeable. It is for this parameter and the union was made.

In the first technological process, the student is invited to make calculations in order to obtain the configuration of the assembly being developed. Here the user can build a table in Excel format, or a mathematical model in the MATLAB software 
package, and then implement the necessary formulas for calculating the kinematic parameters. The creative component lies in the fact that not only the final result, but also intermediate calculation algorithms may differ depending on the task. On this technological process it does not matter at all how exactly the calculations will be carried out. The toolkit is chosen by the student. The teacher only recommends the best practices in this direction.
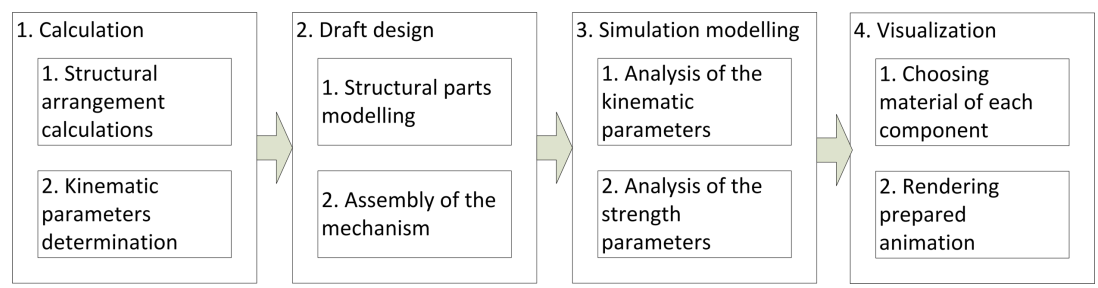

Fig. 4. Technological processes studied during the course work

The second technological process consists of preliminary design. It simulates the shape of the product and its components. The final part of the process is the assembly, according to the dependencies established for the interaction between the assembly elements. The technical design process is intended for visual assessment of the future product in both static and dynamic form. For the construction of 3D-models can be used software at any level. However, it is recommended to use software systems for solid-state modeling, since the next process involves simulation modeling. Such modeling is best done in the same software package where the assembly was developed. This avoids additional conversion between software packages. As the main software package, the SolidWorks system was chosen.

The third technological process is simulation modeling. Here the analysis of the applied forces for each component of the assembly takes place, and also calculations of the real kinematic parameters of the resulting system are made. As a rule, if a highlevel software package was used, then it also includes a simulation package. In our case, SolidWorks perfectly accomplished this task.

The fourth technological process is visualization. At this stage, the final features of the assembly are given, materials are selected, animated videos of the movement of all the components of the system, as well as individual types for the detailed display of the properties of the assembly are rendered. This step can be performed using thirdparty software products and plug-ins, if required.

The aforementioned stage of preparing the model for 3D printing was not mentioned here, since this stage is not included in the mandatory program for mastering the course of 3D graphics. However, in order to test the concept, the student may wish to carry it out, as described in the next section.

Conduct a study of the effectiveness of training in each process. The article discusses the method of assessing the perception of the mastered material. However, this technique is subjective, since the opinion of each respondent may change over time. And although the teacher's assessment methodology by the teacher is also subjective, 
nevertheless, the developed criteria for evaluating each teacher are the same. This suggests that the entire assessment.

The article [5] discusses the method of assessing the perception of the mastered material. However, this technique is subjective, since the opinion of each respondent may change over time. And although the teacher's assessment methodology by the teacher is also subjective, nevertheless, the developed criteria for evaluating each teacher are the same. This suggests that the entire assessment, though subjective, but its level is sufficiently stable.

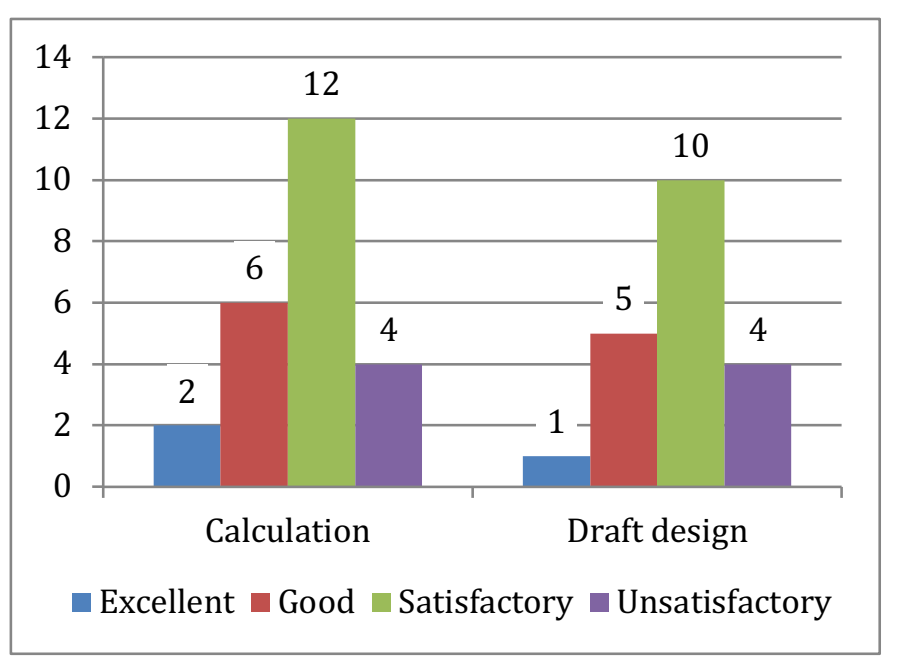

Fig. 5. Student performance using the previous generation study program

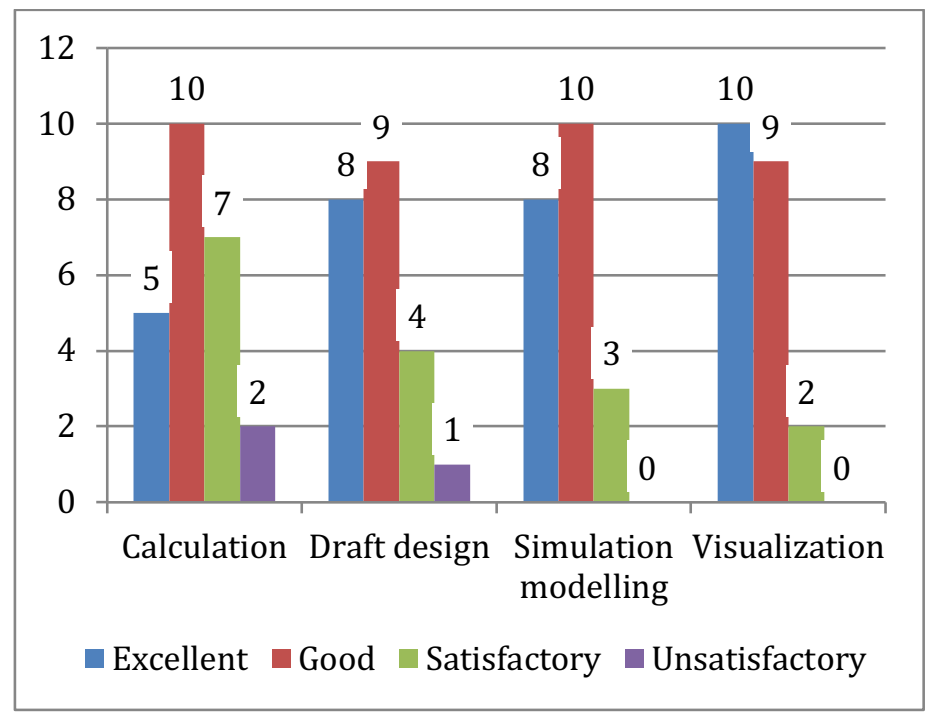

Fig. 6. Student performance using the study program based on developed method 
The study analyzed the performance of students studying the course "Theory of machines and mechanisms" in different years of study. Thus, Figure 5 shows the performance of students before the implementation of the proposed system, and Figure 6 shows the performance after implementation. In both studies, a study group of 23 students was taken. When technological processes 1 and 2 were performed manually, and processes 3 and 4 were not implemented at all.

Technological process 1 was performed manually with minimal use of computer equipment. Most of the calculations were performed on paper, or using a calculator. The process was optimized through the use of mathematical modeling tools and spreadsheets. This significantly reduced routine tasks, and student interest has increased significantly. Figure 6 shows that the number of students who did not cope with the task has decreased. The number of works performed for an excellent assessment has increased.

The technological process associated with the drawings was performed either manually or using obsolete CAD tools. It also played a role in the interest of students and, as a result, in their final grades.

Outdated software and methods for developing drawings did not allow to proceed to the subsequent technological process. For this reason, in the previous program of study, the course project was completed at this stage.

The teaching staff went through advanced training and mastered the proposed methodology in full. Not only the efficiency of student learning increased, but also the efficiency of checking the correctness of all the parameters of the work performed. The technique was tested and showed good results in subsequent groups of students. For example, Figure 6 shows the results of the performance of one of such groups.

Qualitatively increased performance. In the early stages, only two students did not perform satisfactory work and did not move on to the next stage. At the second stage, only one. While at the next stages, students showed brilliant results, because the involvement in the educational process was maximal. It is worth noting that five students have expressed a desire to prepare their work for the manufacture and printing on a 3D-printer. Three of them were able to assemble their 3D printer and test their results in practice.

This approach has proved to be efficient. From 24 people who took the course 21 have created complete 3D models and successfully arrived to the point of the technical implementation of the project. At the same time the constant participation of the teacher in the work of a student group, such as drawings correction and ensuring the input data is correct at every stage of the implementation, is very important. It is recommended to not change the input data of the project a lot for the lower achieving groups but it is possible for high achieving students, so the teacher has two ways of the project development on hand (difficult and easy) at each stage. With the final grade it becomes clear how many and which kind of stages each of the groups has accomplished and based on that the groups that take the course are rated [6]. 


\section{$5 \quad$ Production of the Designed Items}

With their projects the students prepare the lists of commercially available components for their products and calculate the time for production using a 3D printer. The components for printing hardware are mainly purchased abroad, so the list must be prepared by the students on the second month of the work on the project (delivery may take up to three months, considering the logistical risks). Usually the items to order are controllers, actuators, motors, sensors, pumps and other parts of the mechanisms. Further on various fittings and hardware are purchased as well. It is important to mention that the students choose the company to place an order for the components themselves, based on the financial profile of the project.

The business plan of the project is made in Excel and is constantly adjusted based on the changes in pricing up to the moment when all the components are ordered. There is a business plan template for a mechanism prepared for the open online training course.

Enclosure systems and units of mechanisms are made with FDM printing. Cura software is used to prepare control programs, with the real equipment parameters provided as task data. The equipment is installed in the shared use center of the University. Within the open online training course it is possible to use home 3D printers [7].

After checking the 3D model in the STL format for possible defects it is approved for production. Extra requirements are set for the files of this format in order to ensure the correct orientation of the part during the 3D printing (fig. 7). Parts that have not passed checks for correspondence to the production technology requirements are discarded, which is another challenge for the design group within the project.

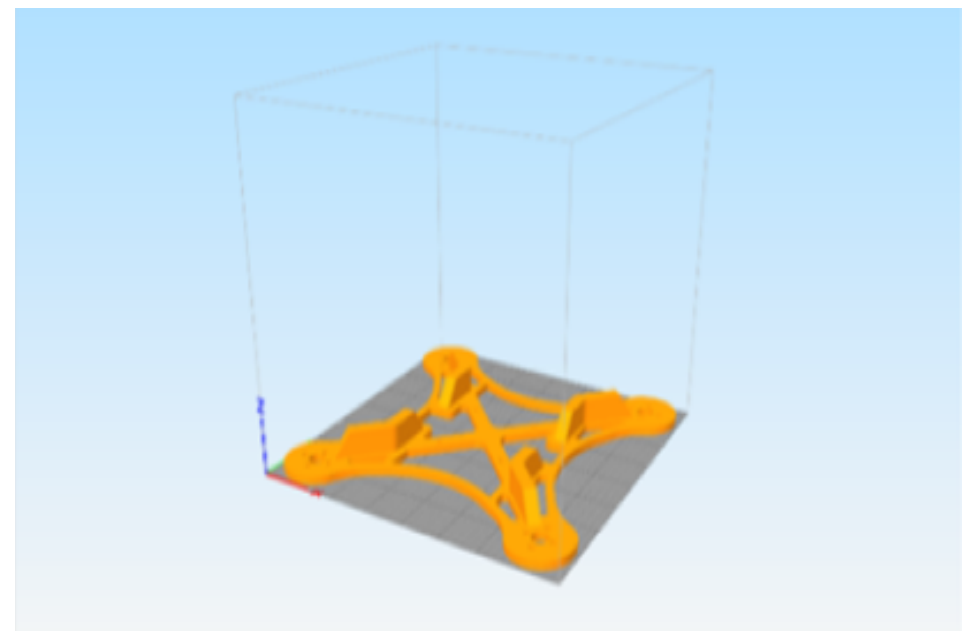

Fig. 7. Part model prepared for 3D printing 
The final stage is the finished product assembly. The assembly is planned by the students beforehand so that it could be done in steps (modular assembly), with partial testing of the part functionality.

One of the key factors of success in a project of this kind turned out to be the students' ability to choose the equipment supplier wisely, reducing the logistical risks. Only four out of seven projects reached the assembly stage on time. Other projects either did not receive the components (key assembly components were either lost by the mail service or did not arrive on time).

In such case even the projects that did not reach the assembly received positive rating because the negative result when the reasons are understood and the situation is analyzed in detail is still a great learning experience for the students.

Within this model we are planning to develop an open online training course which would help to learn the basic theory of the machines and mechanisms. At the same time the students can make the mechanisms on their own (the cost of a home 3D printer today is about 200 USD), and the best mechanisms may be made in the University shared use center and sent by mail to the most promising students.

The students' works may be included in the course as a task for cross-validation to boost their self-esteem. The result of the project may be a video posted on YouTube with a presentation of a finished mechanism or a more complex project [8].

\section{Result and Conclusion}

The proposed technology of learning a technical subject, involving the prototype of a real product may become the most popular in the nearest future, because it allows the students to see the results of their design and calculations.

The technology was tested on a small group (twenty-four students) and has shown good results: the students remained involved in the projects implementation during the whole duration of the project activities and reacted actively to their success and failures during the implementation. Theoretical material of the training course was made in "Moodle".

The big advantage of the presented method is the introduction of the principle of separation of technological processes in time. This gives the student also to understand the basic principles of the conveyor production of the product.

The article highlights separately taken technological processes of the technique using modern CAD and CAM technologies. This has significantly reduced the routine tasks that occur both during training and in production. Among other things, the main achievement is the high involvement of students in these processes. This is evidenced by their high performance. The undoubted motivational factor is the ability to test the resulting product in practice by printing it on a $3 \mathrm{D}$ printer. Despite the fact that the actual production of the product is not a prerequisite for the completion of the project, students show a high interest in the final stage of production.

Similar learning may create an immersive professional learning environment for the students and develop not just the engineering design skills but the understanding 
of the product life cycle and the risks arising in real life, as well as ways to minimize them.

Thus, the possibility of distance learning for technical and engineering professions in higher education today can be partly solved by the design and development of virtual laboratory exercises in the engineering disciplines, as well as remote access to the experimental stands at engineering universities, academic institutes and plants in related industries.

This requires active involvement of students and teachers to mastering of modern hardware and software technologies in distance learning. These technologies can be used not only for laboratory work and practical training, but also for course and diploma design works, as well as for the preparation of undergraduate and master's theses.

\section{$7 \quad$ References}

[1] Ukhov P.A., Lomakin A.L. Distance educational technologies in high school. - Publishing house: MGTA, 2010. - $180 \mathrm{p}$.

[2] Khoroshko L.L., Ukhov P.A., Khoroshko A.L. The Use CAD/CAESystems to Create ELearning Courses on Technical Subjects at University. International Journal of Engineering Pedagogy (iJEP), 2018, Volume 8, No. 2, pp. 64-71. ISSN: 2192-4880. https://doi.org/ 10.3991/ijep.v8i2.8134

[3] Khoroshko L.L., Sukhova T.S. The use of virtual and remote laboratory exercises in engineering education with e-Learning. Proceedings of "15th International Conference on Interactiv Collaborativ Learning and 41st International Conference on Engineering Pedagogy", Austria, Villach, 2012. IEEE Catalog Number: CFP1223R-USB, ISBN: 978-14673-24267.

[4] Ukhov P.A., Lomakin A.L. Distant learning technology in college: Monography, Moscow humanistic technical Academy - M: Publishing house of MHTA, 2010. - 180 p.

[5] Uziak J., Kommula V. Application of Problem Based Learning in Mechanics of Machines Course //International Journal of Engineering Pedagogy. - 2019. - T. 9. - №. 1. - C. 6883. https://doi.org/10.3991/ijep.v9i1.9673

[6] Popov V.B. Fundamentals of information and telecommunication technologies. Multimedia. - Moscow: Finance and Statistics, 2009. - 336 p.

[7] Balyberdin Y.A. Creation of the enterprise information management system model taking into account the requireemnts of Human Capital Developing/Tools and systems. Management, control, diagnostics M.: Publishing house "Nauchtekhlitizdat", 2010. - p. 52-54.

[8] Kibzun A.I., Naumov A.V., Mkhitaryan G.A. Features and technologies of development of the distance learning mathematical disciplines systems CLASS.NET//"Modern information technology and IT education". Vol.1 (№11). - 2015. - p.153 - 156.

\section{Authors}

Leonid L. Khoroshko, Associate Professor, PhD, Head of the Department of System Modeling and Computer-Aided Design, Moscow Aviation Institute (National Research University). He is the author and developer of electronic training courses on technical subjects at the university. He often works as an author and reviewer of pub- 
lications of international conferences (ICL, EDUCON, EDUNINE, WorldCIST, TALE, SDF)

Peter A. Ukhov, Peter A. Ukhov, Associate Professor, PhD, Head of e-learning department, Moscow Aviation Institute (National Research University), management of online learning projects based on Moodle, OpenEdx and its own training systems. Teacher of technical disciplines: metrology, measuring systems, standardization and theory of machines and mechanisms.

Pavel P. Keyno, Associate Professor, PhD, Department System modeling and computer-aided design, Moscow Aviation Institute (National Research University). $\mathrm{He}$ often works as an author of publications of international conferences.

This article is a revised version of a paper presented at the LWMOOCS V conference held at UNED, Madrid, Spain, 26-28 September 2018. Article submitted 2019-01-22. Resubmitted 2019-03-16. Final acceptance 2019-03-16. Final version published as submitted by the authors. 